\title{
PENERAPAN PRODUKSI BERSIH SEBAGAI STRATEGI PENGHEMATAN PENGGUNAAN AIR BERSIH DI PUSKESMAS PUCANG SEWU SURABAYA
}

\author{
Muhammad Al Kholif ${ }^{1)}$ dan Pungut Asmoro ${ }^{2)}$ \\ ${ }^{1)}$ dan ${ }^{2)}$ Program Studi Teknik Lingkungan; Fakultas Teknik Sipil dan Perencanaan \\ Universitas PGRI Adi Buana Surabaya \\ Email : milanisti.alkholif@gmail.com
}

\begin{abstract}
Abstrak
Puskesmas Pucang Sewu merupakan puskesmas perawatan. Observasi awal yang telah dilakukan pada Puskesmas yaitu mengamati kondisi dari masing-masing unit terkait dengan penggunaan kebutuhan air bersih. Kebutuhan air bersih akan berpengaruh terhadap volume limbah yang dihasilkan. Semakin besar kebutuhan air bersihnya, maka semakin banyak limbah cair yang dihasilkan. Produksi bersih merupakan sebuah strategi pengelolaan lingkungan yang bersifat preventif atau pencegahan dan terpadu yang perlu diterapkan secara terus menerus pada proses produksi dan daur hidup produk dengan tujuan mengurangi risiko terhadap manusia dan lingkungan. Masalah dari penelitian ini adalah berapa besar efisiensi penggunaan air bersih pada unit-unit yang ada di Puskesmas Pucang Sewu. Metode yang digunakan dalam penelitian ini adalah dengan metode survey lapangan dengan menganalisis seluruh kebutuhan air bersih pada seluruh aktivitas di Puskesmas Pucang Sewu dan analisis sampel inlet dan outlet air limbah puskesmas. Hasil yang diperoleh menunjukan bahwa jumlah kebutuhan air bersih secara keseluruhan yang ada pada Puskesmas Pucang Sewu terbilang cukup besar yaitu mencapai 4,48 $\mathrm{m}^{3} /$ hari. Hal ini jelas melampaui jumlah kebutuhan air bersih untuk sektor puskesmas yang hanya mencapai $2 \mathrm{~m}^{3} /$ hari. Kapasitas limbah cair yang dihasilkan cukup besar yaitu sebesar 3,58 $\mathrm{m}^{3} /$ hari. Parameter limbah cair yang dianalisis masih memenuhi baku mutu limbah cair yang ditetapkan oleh Gubernur Jawa Timur no 72 tahun 2013 terutama parameter BOD dan COD.
\end{abstract}

Kata Kunci : Kebutuhan Air Bersih, Produksi Bersih, Puskesmas Pucang Sewu

\begin{abstract}
PHC Pucang Sewu is a health clinic treatment. Preliminary observations have been conducted on the health center which is subject to the condition of each unit associated with the use of clean water needs. Need for clean water will affect the volume of waste generated. The greater the need for clean water, the more wastewater produced. Clean production is an environmental management strategy that is both preventive and integrated that need to be applied continuously in production processes and product life cycle with the aim of reducing risks to humans and the environment. Problems of this experiment is how much the efficiency of water use on units that exist in the health center Pucang Sewu. The method used in this research is the field survey method by analyzing the entire need for clean water in all activities in the health center Pucang Sewu and analysis of samples of waste water inlet and outlet clinic. The results obtained show that the number of overall water needs that exist in the health center Pucang Sewu is quite large, reaching $4.48 \mathrm{~m}^{3} /$ day. This clearly exceeded the required amount of clean water to health centers sector which only reaches $2 \mathrm{~m}^{3} /$ day. The capacity of wastewater produced quite large, amounting to $3.58 \mathrm{~m} 3$ / day. Parameters analyzed liquid waste still meet effluent standards set by East Java Governor No. 72 of 2013 mainly BOD and COD parameters.
\end{abstract}

Keywords: Needs Clean Water, Clean Production, PHC Pucang Sewu 


\section{PENDAHULUAN}

Produksi bersih adalah strategi pengelolaan lingkungan yang sifatnya mengarah pada pencegahan (preventif) dan terpadu agar dapat diterapkan pada seluruh siklus produksi. Hal tersebut memiliki tujuan untuk meningkatkan produktivitas dengan memberikan tingkat efisiensi yang lebih baik dalam penggunaan bahan mentah, energi dan air, mendorong performansi lingkungan yang lebih baik melalui sumber-sumber pembangkit limbah dan emisi serta mereduksi dampak produk terhadap lingkungan melalui rancangan yang ramah lingkungan, namun efektif dari segi biaya. Penerapan produksi bersih umumnya dilakukan dalam suatu kegiatan industri untuk tujuan efesiensi dan peningkatan keuntungan, namun tetap memperhatikan kelestarian lingkungan. Meskipun demikian opsi-opsi produksi bersih pada skala rumah sakit ataupun puskesmas dan klinik kesehatan seperti penggunaan air bersih perlu untuk dikaji. Hal ini dimaksudkan agar diperoleh solusi penerapan produksi bersih yang ideal jika kegiatan ini berkembang dan meluas, sehingga dampak-dampak negatif dari keberadaan kegiatan ini bisa diminimalisir (Ma'ruf, M. dkk, 2013).

Pengamatan penerapan produksi bersih ini lebih mengarah kepada konsep zero waste bukan pada pendekatan end of pipe. Limbah cair yang dihasilkan oleh puskesmas bukan merupakan limbah yang membahayakan lingkungan, namun ada pemanfaatan sumber daya yang tidak efektif dan efisien (Probowati Diyah B dan Burhan, 2011). Menurut Afmar (1998), fokus penerapan produksi bersih adalah pada pencegahan terbentuknya limbah. Usaha awalnya berupa pencegahan awal (source reduction), pengurangan terbentuknya limbah (waste reduction) dan pemanfaatan limbah melaui daur ulang (recycle). Keberhasilan ini akan menghasilkan penghematan sehingga terjadi peningkatan efisiensi dan dapat menjadi sumber pendapatan (Anonim, 2007).

Puskesmas Pucang Sewu merupakan salah satu puskesmas yang ada di Kota Surabaya yang terletak di Jalan Pucang Timur Nomor 72 Surabaya. Puskesmas Pucang Sewu merupakan puskesmas perawatan. Status puskesmas tersebut hendak ditingkatkan menjadi puskesmas plus. Puskesmas plus adalah salah satu bentuk pengembangan dari puskesmas yang tidak hanya menitikberatkan pada layanan pengobatan medis (medical services), namun juga mengedepankan penyehatan masyarakat (public health) berupa pembinaan kesehatan masyarakat (pencegahan terjadinya penyakit). Public health dapat dilakukan dengan memberikan penyuluhan, kunjungan ke masyarakat dan lain-lain. Sedangkan fungsi medical sevices diakukan sebagai pelayanan pertama bagi masyarakat yang membutuhkan pengobatan dengan memberikan pelayanan maksimal yaitu adanya unit rawat inap dan tenaga dokter spesialis.

Secara garis besar penelitian ini akan mengidentifikasi sumber-sumber penghasil limbah cair dan menganalisis kebutuhan air bersih di Puskesmas Pucang Sewu yang berpotensi besar menghasilkan limbah cair. Observasi awal yang telah dilakukan pada Puskesmas Pucang Sewu yaitu mengamati kondisi dari masing-masing unit terkait dengan penggunaan kebutuhan air bersih. Kebutuhan air bersih dari masing-masing unit ini akan berpengaruh besar terhadap volume limbah yang dihasilkan. Semakin besar kebutuhan air bersihnya, maka semakin banyak juga limbah cair yang dihasilkan. Tujuannya adalah mengkaji peluang penerapan efisiensi penggunaan air bersih yang berpotensi besar menghasilkan limbah cair sehingga mampu tertampung di Instalasi Pengolahan Air Limbah (IPAL) dengan pengoperasian yang cukup lama. Masalah yang dihadapi di Puskesmas Pucang Sewu adalah belum adanya penerapan produksi bersih yang dilakukan oleh pegawai puskesmas sehingga volume limbah cair yang dihasilkan tidak bisa teroleh dengan baik di IPAL yang dimiliki.

\section{METODOLOGI}

Penelitian ini dilakukan untuk mengkaji peluang penerapan produksi bersih dengan meminimalkan penggunaan air bersih yang berpotensi besar menghasilkan limbah cair. Penelitian dilakukan dengan eksperimen di 
lapangan melalui proses pengamatan atau survei lapangan untuk mendeskripsikan kondisi aktual di lapangan, yang kemudian dibandingkan dengan kondisi ideal untuk mengidentifikasi inefisiensi pemakaian air. Evaluasi peluang yang dapat dilakukan adalah untuk inefiensi pemakaian air yang yang berpotensi besar menjadi limbah dengan menggunakan strategi 1E4R (Elimination, Reduce, Reuse, Recycle, Recovery/Reclaim). Eksperimen lapangan dilakukan untuk menganalisis sumber timbulan limbah. Metode analisis yang digunakan dalam penelitian ini adalah dengan metode survey lapangan dengan menganalisis seluruh kebutuhan air bersih pada seluruh aktivitas di Puskesmas Pucang Sewu dan analisis sampel inlet dan outlet air limbah puskesmas di laboratorium.

Dalam mengidentifikasi sumber inefisiensi, kajian peluang penerapan poduksi bersih dilakukan dalam rangka peningkatan efisiensi pemakaian air bersih pada aktivitas Puskesmas dengan menggunakan strategi 1E4R ( Elimination, Reduce, Reuse, Recycle, Recovery/Reclaim ) (Yuli Gunawan, 2006).

\section{HASIL DAN PEMBAHASAN}

\section{Sumber Daya Manusia (SDM) Puskesmas Pucang Sewu}

World Health Organization (2006) melaporkan bahwa tenaga kesehatan memberikan konstribusi hingga 80\% dalam keberhasilan pembangunan kesehatan dan salah satu jalan terbaik untuk menyelesaikan krisis ketenagaan Sumber Daya Manusia (SDM) Kesehatan yaitu melalui pendidikan dan pelatihan, bersama dengan perbaikan kebijakan manajemen SDM. (Kurniati dan Efendi, 2012). Secara sederhana analisis kebutuhan pegawai merupakan suatu proses analisis yang logis dan teratur untuk mematuhi jumlah dan kualitas pegawai yang diperlukan dalam suatu unit organisasi. Tujuannya agar setiap pegawai pada semua unit organisasi mendapatkan pekerjaan yang sesuai dengan tugas dan wewenang tanggung jawabnya. (Rachmawati, 2008). SDM yang ada pada Puskesmas Pucang Sewu Surabaya secara keseluruhan berjumlah 36 orang.
Jumlah Pengunjung Puskesmas Pucang Sewu

Berdasarkan data primer yang diperoleh dari Puskesmas Pucang Sewu menyatakan bahwa jumlah pengunjung yang akan berobat di Puskesmas tersebut rata-rata berjumlah 160 orang perhari. Jumlah SDM atau pegawai dan jumlah pengunjung ini akan banyak mempengaruhi jumlah kebutuhan air bersih dan banyaknya timbulan limbah cair. Berdasarkan PerMen PU No. 14/PRT/M/2015 tentang Standar Pelayanan Minimal Bidang Pekerjaan Umum dan Penataan Ruang, yaitu kebutuhan air bersih/orang/hari adalah 60 Liter/orang/hari. Sedangkan untuk pengunjung kebutuhan air bersihnya adalah 20 liter/orang/hari. Hal ini jika kebutuhan akan air bersih melebihi perhitungan yang sudah ditetapkan dalam PerMen PU No. 14/PRT/M/2015 maka kapasitas Instalasi Pengolahan Air Limbah (IPAL) tidak bisa menampung timbulan limbah cair yang dihasilkan. Puskesmas Pucang Sewu memiliki sistem pengolahan air limbah teknologi Biofilter Anaerob dengan kapasitas volume IPAL 5,64 $\mathrm{m}^{3}$.

\section{Kebutuhan Air Bersih Puskesmas Pucang Sewu}

\section{a. Kebutuhan Sanitasi Pegawai}

Berdasarkan data yang diperoleh bahwa kebutuhan air bersih untuk kegiatan sanitasi pegawai hanya sebesar 40 L/orang/hari sedangkan kebutuhan air bersih untuk kegiatan sanitasi pengunjung hanya sebesar 10 L/orang/hari. Artinya dengan jumlah kebutuhan air bersih seperti data tersebut sudah sangat jauh dari standar yang ditetapkan oleh PerMen PU No. 14/PRT/M/2015. Jumlah kebutuhan air bersih untuk kegiatan sanitasi pegawai puskesmas dapat dihitung dengan menggunakan perhitungan :

Jumlah tenaga kerja : 36 orang

Kebutuhan air $\quad: 40 \mathrm{~L} / \mathrm{org} / \mathrm{hari}$

Total kebutuhan air bersih:

$=40 \mathrm{~L} /$ org $/$ hari $\times 36$ orang $=1.440 \mathrm{~L} / \mathrm{hari}=1,44$ $\mathrm{m}^{3} /$ hari 


\section{b. Kebutuhan Sanitasi Pengunjung}

Jumlah kebutuhan air bersih untuk kegiatan sanitasi pengunjung puskesmas dapat dihitung dengan menggunakan perhitungan :

Jumlah Pengunjung : 160 orang

Kebutuhan air $\quad: 10 \mathrm{~L} / \mathrm{org} / \mathrm{hari}$

Total kebutuhan air bersih:

$=10 \mathrm{~L} / \mathrm{org} / \mathrm{hari} \times 160$ orang

$=1.600 \mathrm{~L} / \mathrm{hari}$
$=1,6 \mathrm{~m}^{3} /$ hari

\section{c. Kebutuhan Air Bersih Untuk Fasilitas Pendukung}

Kebutuhan air bersih untuk instalasi pendukung Klinik Utama Rawat Inap Husada Buana Surabaya diasumsikan seperti yang diperhatikan pada rincian penggunaan air yang diuraikan pada Tabel 1 berikut.

Tabel 1. Rincian Penggunaan Air untuk Instalasi Pendukung

\begin{tabular}{llc}
\hline No & Jenis Kegiatan & Kebutuhan $\left(\mathbf{m}^{3} / \mathbf{h a r i}\right)$ \\
\hline 1 & Poli gigi & 0,2 \\
\hline 2 & Poli umum & 0,4 \\
\hline 3 & Unit Laboratorium & 0,7 \\
\hline 4 & Dapur/kantin & 0,5 \\
\hline & Jumlah & $\mathbf{1 , 8}$ \\
\hline
\end{tabular}

Kebutuhan air bersih di Puskesmas Pucang Sewu secara keseluruhan digunakan sebagai pemenuhan kebutuhan sanitasi pasien dan, serta untuk pemeliharaan fasilitas kesehatan Puskesmas, pencucian peralatan medis, dan pemeliharaan lingkungan. Jumlah kebutuhan air yang digunakan untuk pemeliharaan diasumsikan sebesar $1 \mathrm{~m}^{3} / \mathrm{hari}$. Secara keseluruhan asumsi perincian kebutuhan air

Tabel 2. Total Kebutuhan Air Bersih Puskesmas Pucang Sewu

\begin{tabular}{clrr}
\hline No & \multicolumn{1}{c}{ Air Bersih } & Jumlah Orang & Kapasitas $\left(\mathbf{m}^{\mathbf{3}} / \mathbf{h a r i}\right)$ \\
\hline 1 & Kebutuhan sanitasi karyawan & 36 & 1,44 \\
\hline 2 & Kebutuhan air untuk fasilitas penunjang & & 1,8 \\
\hline 3 & Pengunjung & 160 & 1,6 \\
\hline \multicolumn{2}{c}{ Total Kebutuhan Air Bersih } & & $\mathbf{4 , 8 4}$ \\
\hline
\end{tabular}

Kapasitas kebutuhan air bersih yang mencapai $4,84 \mathrm{~m}^{3} /$ hari, dapat dikatakan bahwa terlalu besar untuk sektor Puskesmas. Hal ini sudah bisa dipastikan bahwa timbulan limbah cair yang dihasilkan juga akan besar. Air yang digunakan kurang lebih $80 \%$ akan menjadi limbah. Dengan jumlah total kebutuhan air bersih yang ada pada Puskesmas Pucang Sewu yang mencapai $4,84 \mathrm{~m}^{3} /$ hari, maka langkah selanjutnya adalah dengan menghitung jumlah limbah cair domestik yang dihasilkan di Puskesmas Pucang Sewu. bersih dapat dijelaskan dalam Tabel 2 . Sedangkan berdasarkan kriteria perencanaan Ditjen Cipta Karya Dinas PU tahun 1996 dinyatakan bahwa kebutuhan air bersih untuk sektor puskesmas adalah sebesar 2000 liter/hari atau $2 \mathrm{~m}^{3} /$ hari. Tabel 2 merupakan kebutuhan air bersih diberbagai sektor.
Kebutuhan air bersih= $4,48 \mathrm{~m}^{3} /$ hari

Jumlah air limbah yang dihasilkan $=80 \% \times$ jumlah air bersih

Total jumlah air limbah $=80 \%$ x $4,48 \mathrm{~m}^{3} /$ hari $=3,58 \mathrm{~m}^{3} /$ hari

Berdasarkan perhitungan kebutuhan air bersih dan jumlah air limbah yang dihasilkan dari aktivitas di Puskesmas Pucang Sewu maka dapat dijelaskan pada Gambar 1 sebagai berikut. 


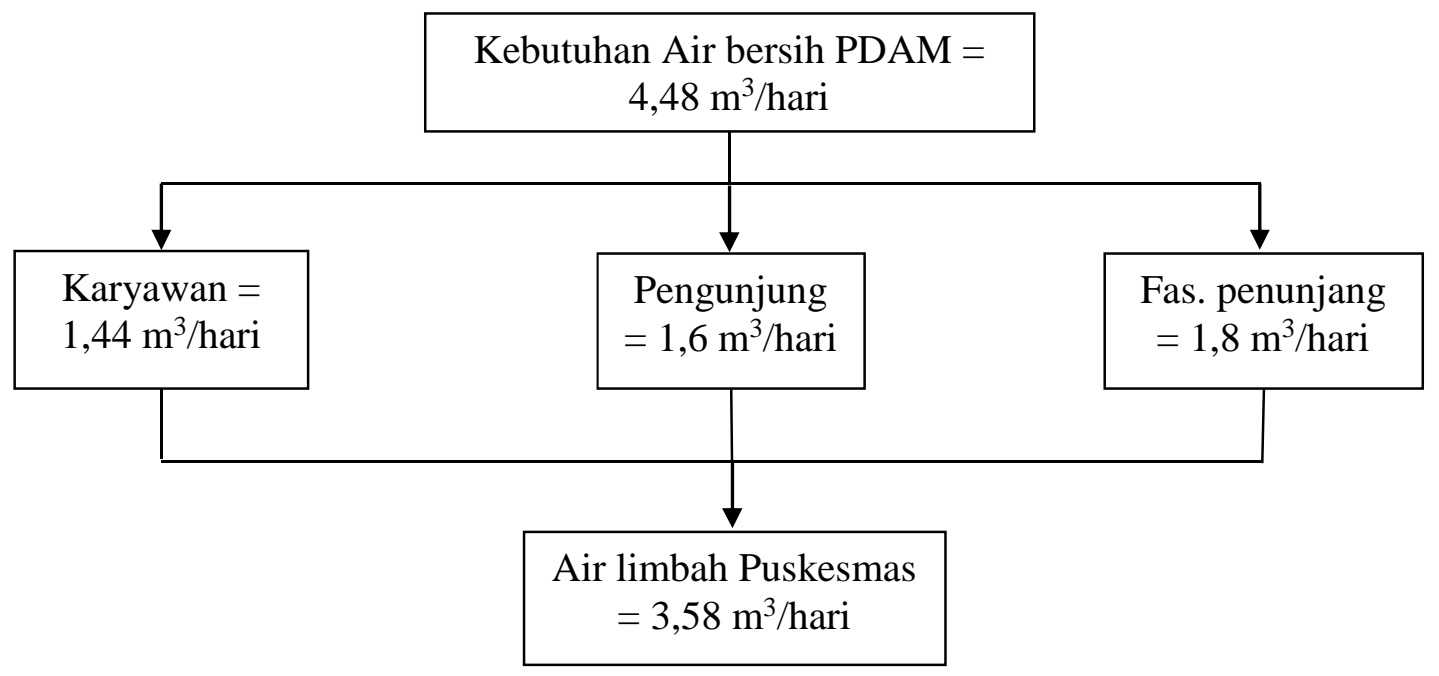

Gambar 1. Neraca Timbulan Air Limbah di Puskesmas Pucang Sewu

Kapasitas IPAL Puskesmas Pucang Sewu sebesar $5,64 \mathrm{~m}^{3}$, maka bisa dipastikan bahwa dengan timbulan limbah puskesmas sebesar 3,58 $\mathrm{m}^{3} /$ hari sudah bisa tertampung dalam IPAL yang ada di Puskesmas Pucang Sewu. Meskipun kebutuhan sanitasi puskesmas secara keseluruhan bisa tertampung di dalam IPAL, namun bukan berarti pada tahun-tahun berikutnya kebutuhan sanitasi Puskesmas secara keseluruhan akan tetap. Dilihat dari data pengunjung yang semakin meningkat pertahunnya, maka tidak bisa dipungkiri kebutuhan air bersih di tahun-tahun berikutnya akan bertambah. Jika hal ini tidak dilakukan penghematan sejak dini, maka kapasitas IPAL yang mencapai $5,64 \mathrm{~m}^{3}$ tidak akan bisa menampung limbah yang dihasilkan dari kegiatan di puskesamas tersebut. Kapasitas air limbah puskesmas relatif kecil sehingga perlu di kembangkan teknologi pengolahan air limbah puskesmas yang murah, mudah operasinya serta harganya terjangkau (Rhenny, dkk, 2014).

\section{Timbulan Limbah di Puskesmas Pucang Sewu}

Timbulan limbah cair yang dihasilkan di Puskesmas Pucang Sewu bersumber dari beberapa unit seperti poli gigi, poli KB, poli umum, unit laboratorium, toilet dan dapur. Sistem pengolahan limbah yang diterapkan di Puskesmas Pucang Sewu adalah dengan menggunakan sitem biofilter anaerob. Pengolahan dengan sistem biofilter anaerob dilakukan karena pengolahan dengan jenis ini dapat mengolah limbah cair dengan baik pada karakteristik yang tinggi atau yang rendah. Selain itu biaya yang diperlukan dalam pengolahan terbilang murah karena tidak membutuhkan asupan energi dalam proses pengolahannya. Limbah yang bersumber dari toilet merupakan penyumbang terbanyak pada Puskesmas ini. Jumlah toilet yang ada di Puskesmas Pucang Sewu yaitu berjumlah 6 toilet dengan rincian 4 toilet/kamar mandi di lantai 1 (satu) dan 2 toilet/kamar mandi di lantai 2 (dua). Dengan demikian sudah bisa dipastikan bahwa dengan banyaknya keberadaan toilet, maka akan semakin banyak juga kebutuhan air bersih yang kemudian berpotensi besar akan menjadi limbah.

Berdasarkan data yang diperoleh dari hasil analisis sampel inlet di laboratorium dinyatakan bahwa masih terdapat beberapa parameter yang tidak memenuhi baku mutu limbah puskesmas berdasrkan keputusan Gubernur Jawa Timur no 
72 tahun 2013. Tabel 3 berikut merupakan data analisis sampel inlet pada Puskesmas Pucang Sewu.

Tabel 3. Analisis Sampel Inlet pada Puskesmas Pucang Sewu

\begin{tabular}{cccc}
\hline Parameter & Satuan & Baku Mutu *) & Hasil Analisis \\
\hline Temperature & ${ }^{0} \mathrm{C}$ & 30 & 25 \\
\hline $\mathrm{pH}$ & - & $6-9$ & 7,30 \\
\hline $\mathrm{TSS}$ & $\mathrm{mg} / \mathrm{L}$ & 30 & 48,00 \\
\hline $\mathrm{COD}$ & $\mathrm{mg} / \mathrm{L} \mathrm{O} \mathrm{O}_{2}$ & 80 & 58,00 \\
\hline $\mathrm{BOD}$ & $\mathrm{mg} / \mathrm{L} \mathrm{O}_{2}$ & 30 & 36,00 \\
\hline $\mathrm{NH}_{3}$ bebas & $\mathrm{mg} / \mathrm{L} \mathrm{NH} \mathrm{N}_{3}-\mathrm{N}$ & 0,1 & 80,91 \\
\hline Pospat & $\mathrm{mg} / \mathrm{L} \mathrm{PO}_{4}-\mathrm{P}$ & 2 & 2,15 \\
\hline Total Koliform & $\mathrm{MPN} / 100 \mathrm{~mL}$ & 10.000 & $24 \times 10^{11}$ \\
\hline
\end{tabular}

\section{Hasil Analisis Sampel Outlet Limbah Cair Puskesmas Pucang Sewu}

Selain menghitung kebutuhan air bersih dan timbulan limbah cair yang dihasilkan pada Puskesmas Pucang Sewu, pada penelitian ini juga dilakuakan analisis sampel pada outlet IPAL. Parameter yang dianalisis merupakan parameter utama limbah yaitu parameter Chemical Oxygen Deman (COD) dan Biological Oxygen Deman (BOD). Jika dilihat dari tabel 4 pada analisis parameter COD dan tabel 5 pada analisis parameter BOD dapat dikatakan bahwa hasil analisis sudah memenuhi baku mutu limbah berdasarkan Peraturan Gubernur Jawa Timur No. 72 Tahun 2013 tentang Baku Mutu Air Limbah Bagi Industri dan/atau Kegiatan Usaha Lainnya. Pada parameter COD nilai terendah analisis terjadi pada hari pertama pengamatan yaitu sebesar 38,20 $\mathrm{mg} / \mathrm{L}$ sedangkan pada hari selanjutnya terbilang stabil, namun masih tetap memenuhi baku mutu yang ditetapkan.

Tabel 4. Hasil Perhitungan Analisis Parameter COD

\begin{tabular}{cc}
\hline Hari Ke & Hasil Analisis $(\mathbf{m g} / \mathbf{L})$ \\
\hline 1 & 38,20 \\
\hline 2 & 40 \\
\hline 3 & 50 \\
\hline 4 & 50 \\
\hline 5 & 52 \\
\hline 6 & 46 \\
\hline
\end{tabular}

Tabel 5. Hasil Perhitungan Analisis Parameter BOD

\begin{tabular}{cc}
\hline Hari Ke & Hasil Analisis (mg/L) \\
\hline 1 & 21,38 \\
\hline 2 & 24,5 \\
\hline 3 & 25,48 \\
\hline 4 & 17,6 \\
\hline 5 & 14,7 \\
\hline 6 & 19,6 \\
\hline
\end{tabular}

Sedikit berbeda dengan apa yang dihasilkan pada analisis BOD. Pada analisis BOD keseluruhannya masih memenuhi baku mutu limbah yang sudah ditetapkan. Berdasarkan hasil analisis diperoleh bahwa nilai terendah yaitu sebesar $14,7 \mathrm{mg} / \mathrm{L}$ sedangkan nilai tertinggi sebesar 25,48 mg/L. Sehingga dapat dikatakan bahwa baik untuk analisis parameter COD dan BOD yang dihasilkan dari outlet IPAL biofilter anaerob pada Puskesmas Pucang sewu seluruhnya masih memenuhi baku mutu yang ditetapkan berdasarkan Peraturan Gubernur Jawa Timur No. 72 Tahun 2013 tentang Baku Mutu Air Limbah Bagi Industri dan/atau Kegiatan Usaha Lainnya.

\section{KESIMPULAN}


Hasil analisis dapat disimpulkan bahwa jumlah kebutuhan air bersih secara keseluruhan yang ada pada Puskesmas Pucang Sewu mencapai $4,48 \mathrm{~m}^{3} /$ hari. Hal ini jelas melampaui jumlah kebutuhan air bersih untuk sektor puskesmas yang hanya mencapai $2 \mathrm{~m}^{3} /$ hari. Kapasitas limbah cair yang dihasilkan cukup besar yaitu sebesar $3,58 \mathrm{~m}^{3} /$ hari. Meskipun limbah cair yang dihasilkan masih bisa tertampung dan terolah dalam IPAL biofilter $\left(5,64 \mathrm{~m}^{3}\right)$, namun pengantisipasian timbulan limbah yang lebih besar dikemudian hari harus sudah dilakukan mulai saat ini. Secara garis besar parameter limbah cair yang dianalisis masih memenuhi baku mutu limbah cair yang ditetapkan oleh Gubernur Jawa Timur No. 72 Tahun 2013 terutama parameter BOD dan COD.

\section{UCAPAN TERIMA KASIH}

Peneliti mengucapkan terima kasih kepada kepala Puskesmas Pucang Sewu dan Dinas Kesehatan Kota Surabaya atas dukungannya kepada peneliti selema melakukan penelitian serta LPPM Universitas PGRI Adi Buana Surabaya yang telah mendanai penelitian ini.

\section{DAFTAR PUSTAKA}

Afmar M, 1998. Faktor Kunci dan Efektif Penerapan Cleaner Production di Industri. Prosiding Seminar Teknik Kimia Bandung. Jurusan Teknik Kimia dan dan Himpunan Mahasiswa Teknik Kimia ITB 1999. Halaman II.15-II.22.

Anonim. 2007. Pengelolaan Limbah Industri Pangan. Direktorat Jenderal Industri Kecil Menengah. Departemen Perindustrian. Jakarta.

Kurniati, A dan Efendi, F. 2012. Kajian SDM Kesehatan di Indonesia. Salemba Medika. Jakarta.

Ma'ruf M, Komasanah Sukarti, Elly Purnamasari, dan Erlan Sulistianto, 2013. Penerapan Produksi Bersih Pada Industri Pengolahan Terasi Skala Rumah Tangga di Dusun Selangan Laut Pesisir Bontang. Jurnal Ilmu Perikanan Tropis Volume 18 Nomor 2: Halaman 84-93

Peraturan Menteri Kementerian Pekerjaan Umum dan Perumahan Rakyat Nomor 14 /PRT/M/2015 Tentang Kriteria dan Penetapan Status Daerah Irigasi Tahun 2015.

Peraturan Gubernur Jawa Timur Nomor 72 Tahun 2013 tentang Baku Mutu Air Limbah Bagi Industri dan/atau Kegiatan Usaha Lainnya Tahun 2013

Probowati Diyah B dan Burhan, 2011. Studi Penetapan Produksi Bersih Untuk Industri Kerupuk. Jurnal Agrointek Volume 5 Nomor 1: Halaman 74-81

Rachmawati, I. K. 2008. Manajemen Sumber Daya Manusia. ANDI. Yogyakarta.

Rhenny Ratnawati, Muhammad Al Kholif dan Sugito, 2014. Desain Instalasi Pengolahan Air Limbah (IPAL) Biofilter Untuk Mengolah Air Limbah PoliPuskesmas Unipa Surabaya. Jurnal Teknik Waktu, Volume 12 Nomor 2 Edisi Juli 2014 ISSN : 1412-1867. Halaman 73-82.

Yuli Gunawan, 2006. Peluang Penerapan Produksi Bersih Pada Sistem Pengolahan Air Limbah Domestic Waste Water Treatment Plant \#48, Studi Kasus di PT Badak NGL Bontang. Tesis Program Studi Ilmu Lingkungan Universitas Dipenogoro, 2006. 